\title{
Using electronic data capture for cardiovascular electrophysiology invasive procedures: An important step towards interoperable clinical registries
}

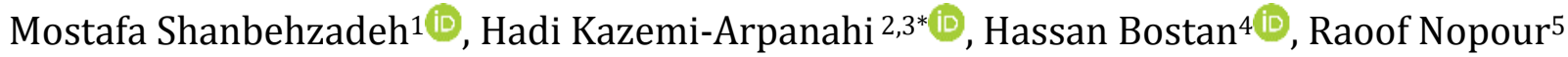 \\ ${ }^{1}$ Assistant Professor, Department of Health Information Technology, School of Paramedical, Ilam University of Medical Sciences, Ilam, Iran \\ ${ }^{2}$ Assistant Professor, Department of Health Information Technology, Student Research Committee, Abadan Faculty of Medical Sciences, \\ Abadan, Iran \\ ${ }^{3}$ Assistant Professor, Head of Student Research Committee, Abadan Faculty of Medical Sciences, Abadan, Iran \\ ${ }^{4} \mathrm{MSc}$ of Health Information Technology, Department of Health Information Technology, Abadan Faculty of Medical Sciences, Abadan, Iran \\ ${ }^{5}$ MSc of Health Information Technology, Department of Health Information Technology and Management, School of Allied Medical Sciences, \\ Tehran University of Medical Sciences, Tehran, Iran
}

\begin{tabular}{ll}
\hline Article Info & A B S T R A C T \\
\hline $\begin{array}{l}\text { Article type: } \\
\text { Research }\end{array}$ & Introduction: The capture and integration of structured data from point of \\
& care into clinical registries has been a challenge. However, this effort is \\
& very important toward a qualitative patient care and research. Collection, \\
& organization and interpretation of clinical data can help to improve \\
Article History: & evidence-based medicine practices. Worksheets data capture are prevalent, \\
Received: $2020-08-27$ & but, not flexible, protected, workflow pleasant, and user friendly and do not \\
Accepted: $2020-10-13$ & support the creation of standardized and interoperable data. The aim of \\
Published: $2020-10-21$ & this study was to design and implement an electronic data capture (EDC) \\
& instrument to be use in context of cardiovascular electrophysiology \\
* Corresponding author: & invasive procedures. \\
Hadi Kazemi-Arpanahi &
\end{tabular}

Assistant Professor, Department of Health Information Technology, Abadan faculty of Medical Sciences, Abadan, Iran

Email: H.kazemi@abadanums.ac.ir

Keywords:

Electronic Data Capture

EDC

Clinical Registry

Electrophysiology

REDCap
Material and Methods: This descriptive and developmental study conducted in three phases as follows. 1) data standardization according national and international data element templates published by specialized societies; 2) developing of an initial data collection and clinical research workflow 3), establishing of electronic case reports using Research Electronic Data Capture (REDCap) in accordance with the Health Insurance Portability and Accountability Act (HIPAA) privacy rule.

Results: Three case report forms was developed that included demographics, medical history, physical examination, laboratory tests, imaging procedures, electrophysiology (EP) procedures, as well as medications and follow-up information. Data-entry validation criteria have been implementing in electronic data collection instrument to assure validity and precision when data enter in electronic form.

Conclusion: This paper describes the process used to create an EDC application. Data collection applications were successfully develop as an a priori step in a clinical research for assisting data collection and management in a case of cardiovascular EP invasive procedures.

Cite this paper as:

Shanbehzadeh M, Kazemi-Arpanahi H, Bostan H, Nopour R. Using Electronic Data Capture for Cardiovascular Electrophysiology Invasive Procedures: An Important Step Towards Interoperable Clinical Registries. Front Health Inform. 2020; 9: 48. DOI: 10.30699/fhi.v9i1.236

\section{INTRODUCTION}

Quality of medical researches is fully dependent on accuracy and reliability of collected data. Data integration in to clinical research systems in proper way can be a considerable challenge. Clinical research often poorly integrated with clinical care practice and it resulting in redundant repetition of work and limits learning from clinical practice $[\underline{1}, \underline{2}]$.
One important step in medical research is accurate and reliable collection of data to ensure valid results. The validity and reliability of any research project depends on accuracy of collected data [3, 4]. Manual Data entry in clinical registry can be a time consuming, resources intensive and possible error prone process. Furthermore, design a data management solution is often a significantly 
challenge [ $\underline{5}$.

As a special kind of clinical research systems, clinical registries have been consideration in this study. Investigations conducted based on high quality clinical registries can present an actual assessment of clinical practice, difference in treatment and consequences, describe patterns of care, and examine factors that influence prognosis and quality of life [ $\underline{6}, \underline{7}]$. Irrespective of its huge potential for both biomedical research as well as the potential to affect clinical practice and healthcare strategies, clinical registries frequently bounded by process problems that significantly lessening their importance $[\underline{8}, 9]$. These include missing data and poor data quality, which related to how the research component of the registry aligned with clinical workflow and how personnel involved in the data collection trained $[\underline{10}, \underline{11}]$.

Lack of coordination between the clinical and research workflows is time consuming for clinical staff, healthcare policy maker and researcher. In addition, many hospitals and healthcare facilities that participate in studies, present different data capture systems for both healthcare and research settings resulting in island performance, effort duplication, and ultimately leading to data inconsistency [12-14].

To improve the quality of data in clinical registry and decrease the percentage of errors, healthcare organizations should follow certain structured measures to decrease inaccurate and incomplete data [15-17]. Therefore, in order to alignment the clinical data collection with the medical researches, EDC software is required to improve the efficiency and quality of data. It is a way to enter data from point of care electronically, instead use of traditional paper forms $[18,19]$.

REDCap software (https://projectredcap.org), is widely available under an authorization provided by Vanderbilt University [이, 21] . This software meets the requirements of HIPPA [22]. In addition, export data for analysis and reporting is compatible with several statistical packages, and easy to use are some features of REDCap software [23] . Besides, REDCap data validation measures can prevent data entry errors and non-integration through define standard data format and content normal ranges [24]. REDCap also supports detailed user permission controls so that study personnel can be limited in how they interact with the data [25]. For statistical analyses, data stored in REDCap can export into a variety of statistical software formats. This feature improved the study team's efficiency when automatic data entering into Statistical Package for the Social Sciences (SPSS) by independence to errorprone manual data entry [26].

As increasing data quality is a remaining concern in healthcare researches and accurate, structured and automatic data entry process is essential for carrying out high-quality research; hence the aim of this study is to design an instrument that can serve as a convenient and reliable tool in data collection, storage, management, and interpretation to facilitate clinical research. We sought to implement a webbased EDC system for routine clinical care, using structured data entry to improve the ease of clinical documentation, and simultaneously establish a population based EPS database to facilitate outcomes reporting.

\section{MATERIAL AND METHODS}

In this study, we are creating EDC template to gathering and analysis data of cardiovascular invasive EP procedures (pacemaker, Implantable Cardioverter-Defibrillator (ICD), and catheter ablation). Patients who are undergoing cardiovascular invasive EP procedures are qualified to be included in this registry. To create these instruments, the following steps were undertaken:

\section{Data element standardization}

The first task was determining key clinical data element through standard, available, and approved national or international data element templates. To begin, in cooperate with two cardiologists the data dictionaries of the National Cardiovascular Data Registry (NCDR) and Adult Cardiac Surgery Registry (ACRF) examined. Then methodically studied all of the current existing cardiovascular data dictionaries and standards documents published by specialized societies such as the American Heart Association (AHA), American College of Cardiology (ACC), NCDR and the Iranian cardiovascular registries [ $\underline{27} \underline{28}]$.

\section{Development data collection and research workflows}

At first based on consulting with cardiologist and other employees, data flow and collection intervals in EP department extracted. For this ends, the registry forms designed based on standard categories for each cardiovascular invasive intervention in EP department. Data elements were grouping into nine demographics, medical history, physical examination, laboratory tests, imaging procedures, EP procedures, medical / surgical procedures, medications and follow-up categories. This categories indicate clinical context in which the data elements is expected to be obtained or collected and reflect the usual workflow organization of information in typical clinical settings for single episode of care. Three data capture case report forms where designed and implemented on the REDCap platform to allow the management of data for clinical registries of cardiac invasive EP procedures. 


\section{RESULTS}

\section{EDC forms structuring}

Each data capture form developed in this study consists of demographic characteristics, medical history, physical examinations, laboratory tests, radiology examinations, EP procedures, medications administrated before- during- and after procedure, procedure complications, and follow-up information. The data collection process is done in four time interval including during admission, preoperative, intraoperative and discharge. We observed the changing state of their diseases in one, six, 12 month and then annually after admission (Fig 1). We created a large, prospective, non-interventional database in the registry to collect data describing the management and outcomes of patients who underwent evaluation, intraoperative, discharge from hospital. Then type of data that need to capture in clinical practice and research were determined (Table 1).
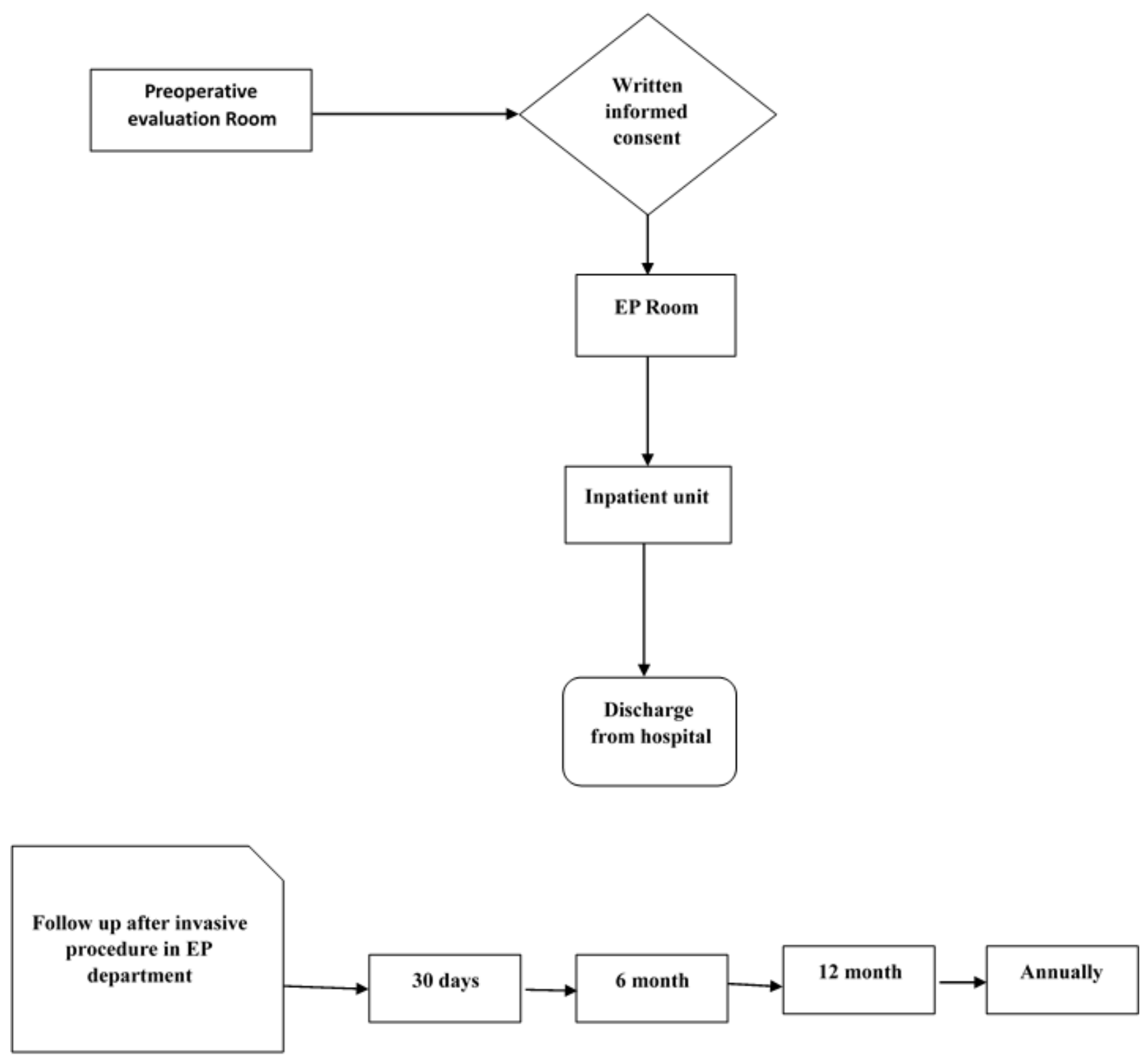

Fig 1: Flow of data collection for the cardiovascular invasive procedures registries 
Table1: Data collection place, interval, corresponding data elements, and their research variables

\begin{tabular}{|c|c|c|c|}
\hline $\begin{array}{l}\text { Data collection } \\
\text { place }\end{array}$ & $\begin{array}{l}\text { Data collection } \\
\text { interval }\end{array}$ & Data elements & Research variables \\
\hline \multirow[b]{2}{*}{$\begin{array}{l}\text { Preoperative } \\
\text { Evaluation } \\
\text { Room }\end{array}$} & Admission & $\begin{array}{l}\text { Demographic data, treatment and } \\
\text { surgery consent }\end{array}$ & $\begin{array}{l}\text { Inclusion / exclusion criteria, ID, } \\
\text { screening , consent to participating in } \\
\text { clinical research }\end{array}$ \\
\hline & $\begin{array}{l}\text { Preoperative } \\
\text { evaluation }\end{array}$ & $\begin{array}{l}\text { Clinical evaluation } \\
\text { Preoperative history } \\
\text { Laboratory tests } \\
\text { Echocardiogram } \\
\text { Electrocardiogram } \\
\text { Chest X-ray } \\
\text { physical examinations } \\
\text { Drug administration prior to } \\
\text { procedure } \\
\text { Qol assessment }\end{array}$ & Data capture based research profiles \\
\hline $\begin{array}{l}\text { EP department } \\
\text { Room }\end{array}$ & $\begin{array}{l}\text { Intraoperative } \\
\text { procedures }\end{array}$ & $\begin{array}{l}\text { Procedure information } \\
\text { Drug administration during } \\
\text { procedure }\end{array}$ & Data capture based research profiles \\
\hline Inpatient unit & $\begin{array}{l}\text { Discharge from } \\
\text { hospital }\end{array}$ & $\begin{array}{l}\text { Cardiac evaluation, pulmonary, } \\
\text { renal, vascular and other } \\
\text { complications following } \\
\text { procedure discharge, Medications } \\
\text { in use, discharge instructions }\end{array}$ & Data capture based research profiles \\
\hline $\begin{array}{l}\text { Clinical } \\
\text { registries } \\
\text { department }\end{array}$ & $\begin{array}{l}\text { Follow up at } 30 \\
\text { days, } 6 \text { month, } \\
12 \text { months, and } \\
\text { annually }\end{array}$ & $\begin{array}{l}\text { Living status, cardiovascular } \\
\text { events, medications in use, }\end{array}$ & Data capture based research profiles \\
\hline
\end{tabular}

\section{Development of EDC forms using REDCap}

The REDCap user interface provides an instinctive method for securely and accurately record of data to research studies. It captured structured data by maximizing the use of drop-down menus, selection boxes, and radio buttons while minimizing catchall fields labeled "Other" with corresponding free-text. Each case report form is accessible only to users who have sufficient access rights set by the research team. Case report forms contain field-specific validation code sufficient to ensure strong data integrity. In addition to checking for obligatory field type (e.g. numeric entry for systolic blood pressure), surrounded functions also check data ranges (e.g. 70-180 $\mathrm{mmHg}$ ) and aware the end-user whenever entered data disrupts specified confines. Data fields may be populated using text fields or through embedded pull-down boxes or radio buttons where the end-user is shown one value and a separate code is stored in the database for later statistical analysis (e.g. $0=\mathrm{No}, 1=\mathrm{Yes}$ ).

With REDCap, we controlled data format/type, set ranges for date and numeric fields, and permitted data validation. Data consistency problems such as incorrect data type, values out of range, and outliers for numerical fields can be report using the data quality module. Further, we applied pre-defined rules that facilitated determination of whether a specific data value might be discrepant, which is very important because our project contains many fields and has many records. Infrastructural requirements such as a web server that supports PHP Hypertext Preprocessor (PHP), a MySQL database server, and Secure Sockets Layer (SSL) connections need to be satisfied (Fig 2 and 3).

\section{Security technical requirements}

The clinical data preserve full patient confidentiality since they are SSL encoded and using Secure Hypertext Transfer Protocol (SHTTP) and Virtual Private Network (VPN) platform and kept on a protected server. All system transactions (documentation, content edition, deleting etc.) supported with the audit trail capabilities. The project administrative can also lock the data after all finalization checks have been complete. Researchers can access the database from multiple sites and institutions only with their own unique usernames and passwords. The project administrator can also allocate different levels of data access privileges to different users, depending on their roles in the project. These rights include logging, data entry rights, managing survey participants, calendar, data export/ import tools, file repository, data quality, project design, and setup. 


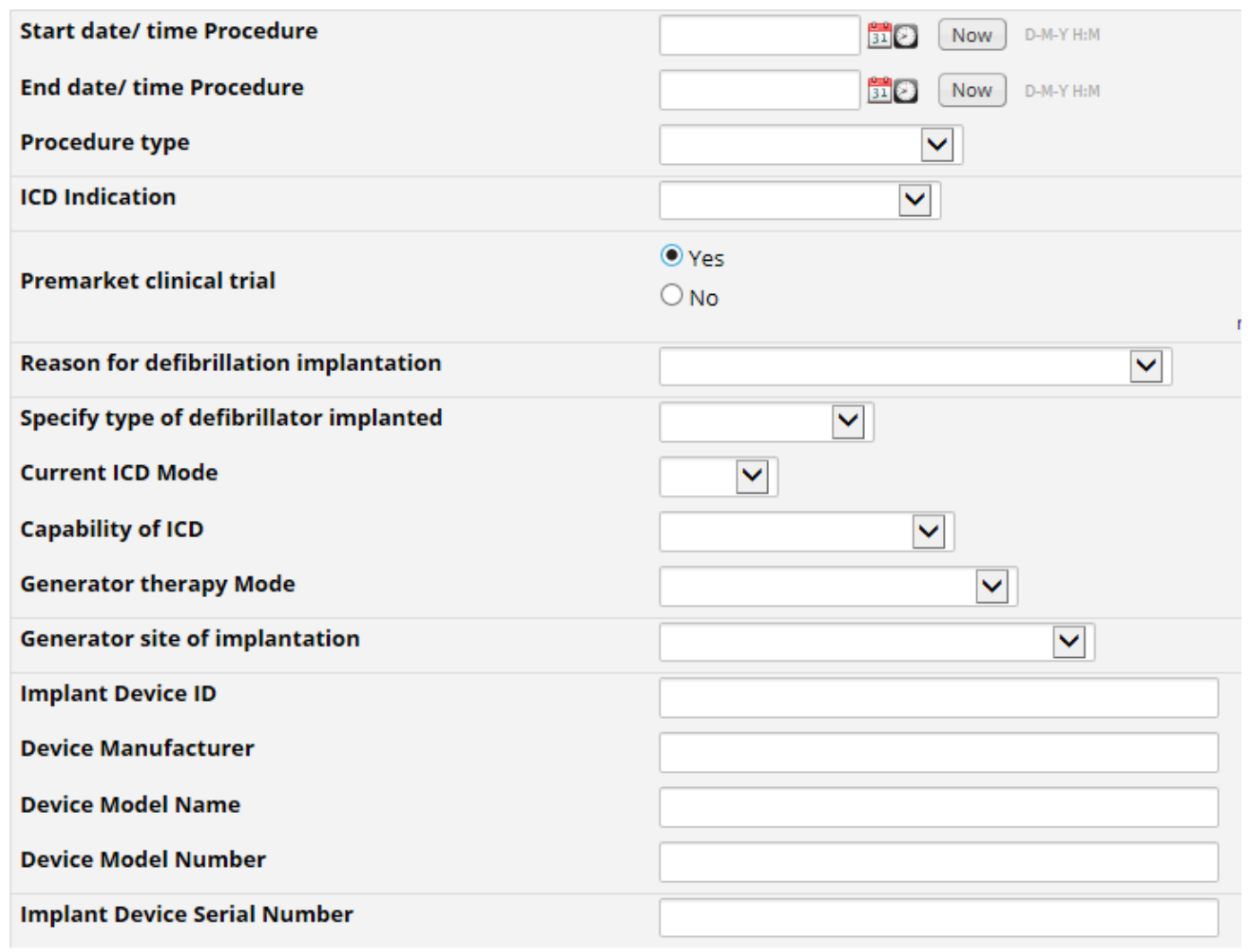

Fig 2: Sample of ICD registry case report form

\begin{tabular}{l|l|l|l|}
\hline Date of procedure \\
Sedation /anesthesia \\
Indication of pacemaker \\
\hline type of pacemaker implanted \\
\hline Venous access \\
\hline capable of pacemaker \\
\hline Endocardial Lead Positions \\
\hline Epicardial lead positions \\
\hline Generator manufacture \\
\hline Generator serial number \\
\hline Generator model
\end{tabular}

Fig 3: Sample of pacemaker registry case report form

\section{Data entry and quality control}

It took a trained medical worker approximately 30 minutes per subject to convert clinical data to the eCRF format used in the REDCap platform. The frequent collection ensured timely and efficient acquisition of the clinical data of the patients of interest, significantly reducing the traditional data collection workload and facilitating future clinical researches. Moreover, since the data collected can easily convert to formats used by Microsoft excel, Microsoft access, SPSS, and Statistical Analysis System (SAS), they are appropriate to transfer and share. For each user determined an electronic signature and nontransferable password, and defined different levels of access for insertion, query and exportation of data. Access to the software could 
be performing from any computer, tablet or smartphone connected to the internet or using the offline version of REDCap.

\section{DISCUSSION}

Health information interoperability is defined the ability to capture, review, share, and reuse electronic health data seamlessly across health system, thus capture of data is important step to design interoperability framework between healthcare systems [29-31]. The preliminary effort to create these three electronic data capture forms is part of a larger program to address the lack of data interoperability between the clinical information systems and clinical registries in field of cardiac EP invasive procedures [르, $\underline{33}]$.

In this paper, we describe the infrastructure required for interoperability between clinical information systems with clinical registries in the field of cardiac EP that involving a diversity of steps such as the alignment between research and clinical workflows, the adoption of clinical data management techniques, the development of electronic data capture using REDCap. This implemented web-based EDC systems, capture structured data from point of care, that leading to improving the efficiency of clinical documentation and prospectively populating clinical registries. These applications are practical for routine clinical use, and estimated a reduction in total documentation time per patient, during a standard course of procedure in cardiac EP department [느36].

A high quality clinical registry can help to accurate monitoring and improve the efficiency of invasive EP procedures. To reach this, these applications can enable the researchers in data management on the context of cardiac EP invasive procedures, because data management is very important in clinical researches [ $\underline{37}-\underline{39}]$.

The main finding of this paper was that less time and effort is required to collect data than traditional tools e.g. spreadsheet. Setting up ranges and automatic calculations can prevent data entry errors and inconsistencies.

The major advantage of electronic Case Report Forms (CRF) over spreadsheets is that the former can be design to present only with certain acceptable choices for an item or to check the syntax and range of data that entered. This reduces the likelihood of data entry errors [40].

Moreover, in this paper we propose an electronic data capture application for enhancing health information systems potential to collect structured and standard based clinical research data during clinical encounters. This application integrates data entry for clinical research into existing clinical documentation workflows, leveraging executable documentation management module to support harmonized, consistent data gathering for both patient care and clinical research.

Traditional data collection for clinical and scientific trials has focused on paper-based CRFs followed by double data entry into a Relational Database (RDB). Recent technological advances and considerable reduction in size, price and efficiency for portable computers (microcomputers e.g. Physician Device Assistant (PDA)) make EDC an intriguing alternative. The major advantages of EDC would be the ability to enter, review and analyze data in real-time and to implement online data validation checks to assure data quality more effectively at the point of entry $[\underline{21}, \underline{40}]$.

REDCap had a very clear advantage due to its extensive tutorials and online training materials [ $\underline{41}$, 42]. The benefits of EDC include direct data entry at the Point of care leading to greater accuracy, fewer queries, declined paper record storage, and timelier population of the study database. Direct data capture improves the accuracy of collected data [43].

Electronic documentation improves legibility and availability of documentations, and it facilitates the collection of structured data for purposes such as quality improvement and research. However, implementing electronic documentation has been reported to adversely impact clinicians' perceptions of documentation quality, workflow, professional communication, and patient care [44].

Data collection in clinical practice and biomedical research domain changed due to emergence of electronic medical record and automatic data capture [45]. These electronic forms lessen inaccurate data entry and study costs because the data entered in parallel to their clinical activities. Also EDC solution remove the limitations of paperbased data collection and increase the quality of data [40].

This development stands to be a huge benefit to researchers, as it will enable them to undertake increasingly sophisticated investigations more easily. However, in order to take advantage of improved data availability, we must first create effective systems to extract, store, utilize, and protect information with thoughtfully designed disease-specific databases and informatics infrastructures [46]. Proposed work for enhancing health information systems to support clinical research builds on the data management solutions, bridging the adoption gap by incorporating them directly into electronic documentation tools [47, 48]. The approach facilitates reuse of routinely collected data and seamless inclusion of data capture specific to a patient's research studies while minimizing the 
impact on clinician effort $[\underline{49}, \underline{50}]$.

\section{CONCLUSION}

This paper represents the required infrastructure of cardiovascular EP invasive procedures registries and the approach taken to its construction and management. Construction of EDC template for cardiovascular EP invasive procedures facilitates better conversion from clinical practice to scientific research. In this way, REDCap offer users a strong data management platform for their study projects. It has enjoyed tremendous growth over the past few years because of its popular design, which facilitates research data collection needs. Such an effort can be widespread to other medical registries.

\section{ACKNOWLEDGEMENTS}

The authors thank the deputy dean of research affairs, Abadan Faculty of Medical Sciences for financially supporting this project.

\section{AUTHOR'S CONTRIBUTION}

The authors agree on this final form of the manuscript, and attested that all authors contributed in the final draft of the manuscript.

\section{CONFLICTS OF INTEREST}

The authors declare no conflicts of interest regarding the publication of this study.

\section{FINANCIAL DISCLOSURE}

This article extracted from a research project supported by Abadan Faculty of Medical Sciences and approved by ethical committee (IR. ABADANUMS.REC.1399.90).

\section{REFERENCES}

1. Iturralde EC, Jardeleza MAB, Zamora-Racaza G, Penserga EG, Caro JD. Design and development of a registry system for primary vasculitis. International Conference on Information, Intelligence, Systems \& Applications. IEEE; 2016.

2. Dunn Jr WD, Cobb J, Levey AI, Gutman DA. REDLetr: Workflow and tools to support the migration of legacy clinical data capture systems to REDCap. Int J Med Inform. 2016; 93: 103-10. PMID: 27396629 DOI: 10.1016/j.ijmedinf.2016.06.015 [PubMed]

3. Hasmasanu MG, Bolboaca SD, Jäntschi L, Zaharie GC, Drugan TC. Design and implementation of data collection instruments for neonatology research. Applied Medical Informatics. 2014; 35(4): 35-44.

4. Barchard KA, Verenikina Y. Improving data accuracy: Selecting the best data checking technique. Computers in Human Behavior. 2013; 29(5): 191722.

5. Alavi CB, Massman JD. Selecting an electronic data capture system. Urology Practice. 2016; 3(3): 23641.

6. Stey AM, Russell MM, Ko CY, Sacks GD, Dawes AJ, Gibbons MM. Clinical registries and quality measurement in surgery: A systematic review. Surgery. 2015; 157(2): 381-95. PMID: 25616951 DOI: 10.1016/j.surg.2014.08.097 [PubMed]

7. van der Veer SN, de Keizer NF, Ravelli AC, Tenkink S, Jager KJ. Improving quality of care: A systematic review on how medical registries provide information feedback to health care providers. Int J Med Inform. 2010; 79(5): 305-23. PMID: 20189451 DOI: 10.1016/j.ijmedinf.2010.01.011 [PubMed]

8. Hirata K, Imamura M, Fujiwara T, Fukui T, Furukawa $\mathrm{T}$, Gotoh $\mathrm{M}$, et al. Current status of site-specific cancer registry system for the clinical researches: aiming for future contribution by the assessment of present medical care. Int J Clin Oncol. 2019; 24(9): 1161-8. PMID: 31011913 DOI: 10.1007/s10147-01901434-w [PubMed]

9. Mojarrab S, Rafei A, Akhondzadeh S, Jeddian A, Jafarpour M, Zendehdel K. Diseases and health outcomes registry systems in I.R.Iran: Successful initiative to improve public health programs, quality of care, and biomedical research. Arch Iran Med. 2017; 20(11): 696-703. PMID: 29480735 [PubMed]

10. da Silva KR, Costa R, Crevelari ES, Lacerda MS, de Moraes Albertini CM, Martinelli Filho M, et al. Glocal clinical registries: Pacemaker registry design and implementation for global and local integrationmethodology and case study. PloS one. 2013; 8(7): e71090. PMID: 23936257 DOI: 10.1371/journal.pone.0071090 [PubMed]

11. Lee P, Chin K, Liew D, Stub D, Brennan AL, Lefkovits J, et al. Economic evaluation of clinical quality registries: A systematic review. BMJ open. 2019; 9(12): e030984. PMID: 31843824 DOI: 10.1136/bmjopen-2019-030984 [PubMed]

12. Danckert B, Horsbøl TA, Andersen O, Dalton SO, Christensen J, Rasted $M$, et al. Registrations of patients with renal cell carcinoma in the nationwide Danish renal cancer database versus the Danish cancer registry: Data quality, completeness and survival (DaRenCa Study-3). Clin Epidemiol. 2020; 12: 807-14. 32801918 DOI: 10.2147/CLEP.S258755 [PubMed]

13. Sajjadnia Z, Khayami R, Moosavi MR. Preprocessing breast cancer data to improve the data quality, diagnosis procedure, and medical care services. Cancer Inform. 2020; 19: 1176935120917955. PMID: $32528221 \quad$ DOI: $\quad 10.1177 / 1176935120917955$ [PubMed]

14. Zutshi M, Aiello A, Fuerst A, Golcher H, Parc Y, Galandiuk S, et al. Reducing patient burden and 
improving data quality with the new cleveland clinic colorectal cancer quality of life questionnaire. Dis Colon Rectum. 2020; 63(4): 469-87. PMID: 32015285 DOI: 10.1097/DCR.0000000000001575 [PubMed]

15. Gliklich RE, Leavy MB. Assessing real-world data quality: The application of patient registry quality criteria to real-world data and real-world evidence. Ther Innov Regul Sci. 2020; 54(2): 303-7. PMID: 32072577 DOI: $\quad 10.1007 / \mathrm{s} 43441-019-00058-6$ [PubMed]

16. Jalloh MF, Namageyo-Funa A, Gleason B, Wallace AS, Friedman M, Sesay T, et al. Assessment of VaxTrac electronic immunization registry in an urban district in Sierra Leone: Implications for data quality, defaulter tracking, and policy. Vaccine. 2020; 38(39): 6103-11.

17. Orlandi BMM, Mejia OAV, Borgomoni GB, Goncharov M, Rocha KN, Bassolli L, et al. REPLICCAR II study: Data quality audit in the Paulista cardiovascular surgery registry. PloS one. 2020; 15(7): e0223343. PMID: 32649718 DOI: 10.1371/journal.pone.0223343 [PubMed]

18. Jibb LA, Khan JS, Seth P, Lalloo C, Mulrooney L, Nicholson $\mathrm{K}$, et al. Electronic data capture versus conventional data collection methods in clinical pain studies: Systematic review and meta-analysis. J Med Internet Res. 2020; 22(6): e16480. PMID: 32348259 DOI: $10.2196 / 16480$ [PubMed]

19. Rorie DA, Flynn RWV, Grieve K, Doney A, Mackenzie I, MacDonald TM, et al. Electronic case report forms and electronic data capture within clinical trials and pharmacoepidemiology. Br J Clin Pharmacol. 2017; 83(9): 1880-95. PMID: 28276585 DOI: 10.1111/bcp.13285 [PubMed]

20. Harris PA, Taylor R, Minor BL, Elliott V, Fernandez M, $O$ 'Neal L, et al. The REDCap consortium: Building an international community of software platform partners. J Biomed Inform. 2019; 95: 103208. PMID: 31078660 DOI: 10.1016/j.jbi.2019.103208 [PubMed]

21. Yamamoto K, Ota K, Akiya I, Shintani A. A pragmatic method for transforming clinical research data from the research electronic data capture "REDCap" to clinical data interchange standards consortium (CDISC) study data tabulation model (SDTM): Development and evaluation of REDCap2SDTM. J Biomed Inform. 2017; 70: 65-76. PMID: 28487263 DOI: 10.1016/j.jbi.2017.05.003 [ubMed]

22. Bowman MA, Maxwell RA. A beginner's guide to avoiding protected health information (PHI) issues in clinical research: With how-to's in REDCap data management software. J Biomed Inform. 2018; 85: 49-55. PMID: $30017974 \quad$ DOI: 10.1016/j.jbi.2018.07.008 [PubMed]

23. Santarem MD, de Oliveira Dias $P$, dos Santos $S$, Rodrigues CG, Goldmeier S. Prospective clinical registry to evaluate clinical outcomes of hypertension patients in a multidisciplinary clinic. Journal of the International Society for Telemedicine and eHealth. 2017; 5: 47-51.

24. Pang X, Kozlowski N, Wu S, Jiang M, Huang Y, Mao P, et al. Construction and management of ARDS/sepsis registry with REDCap. J Thorac Dis. 2014; 6(9): 1293-9. PMID: 25276372 DOI: 10.3978/j.issn.20721439.2014.09.07 [ubMed]

25. O'Keefe AL, Buss BF, Koirala S, Gleason MX, Mudgapalli A, Schwedhelm S. REDCap for biocontainment worker symptom monitoring. Health Secur. 2019; 17(1): 3-10. PMID: 30724610 DOI: 10.1089/hs.2018.0086 [PubMed]

26. Read KB, LaPolla FWZ, Tolea MI, Galvin JE, Surkis A. Improving data collection, documentation, and workflow in a dementia screening study. J Med Libr Assoc. 2017; 105(2): 160-6. PMID: 28377680 DOI: 10.5195/jmla.2017.221 [PubMed]

27. Dehmer GJ, Badhwar V, Bermudez EA, Cleveland JC, Cohen MG, D'Agostino RS, et al. 2020 AHA/ACC key data elements and definitions for coronary revascularization: A report of the American college of cardiology/ American heart association task force on clinical data standards (writing committee to develop clinical data standards for coronary revascularization). J Am Coll Cardiol. 2020; 75(16): 1975-2088. PMID: 32217040 DOI: 10.1016/j.jacc.2020.02.010 [PubMed]

28. Choquet R, Maaroufi M, de Carrara A, Messiaen C, Luigi E, Landais P. A methodology for a minimum data set for rare diseases to support national centers of excellence for healthcare and research. J Am Med Inform Assoc. 2015; 22(1): 76-85. PMID: 25038198 DOI: 10.1136/amiajnl-2014-002794 [PubMed]

29. Dixon BE, Vreeman DJ, Grannis SJ. The long road to semantic interoperability in support of public health: experiences from two states. J Biomed Inform. 2014; 49: 3-8. PMID: 24680985 DOI: 10.1016/j.jbi.2014.03.011 [PubMed]

30. Janaswamy S, Kent RD. Semantic interoperability and data mapping in EHR systems. International Conference on Advanced Computing. IEEE; 2016.

31. Slotwiner DJ, Abraham RL, Al-Khatib SM, Anderson HV, Bunch TJ, Ferrara MG, et al. HRS white paper on interoperability of data from cardiac implantable electronic devices (CIEDs). Heart Rhythm. 2019; 16(9): e107-27. PMID: 31077801 DOI: 10.1016/j.hrthm.2019.05.002 [PubMed]

32. Hur S, Lee J, Kim T, Choi JS, Kang M, Chang DK, et al. An Automated Fast Healthcare Interoperability Resources-Based 12-Lead Electrocardiogram Mobile Alert System for Suspected Acute Coronary Syndrome. Yonsei Med J. 2020; 61(5): 416-22. PMID: 32390365 DOI: $10.3349 /$ ymj.2020.61.5.416 [PubMed]

33. Liyanage H, Krause P, de Lusignan S. Using ontologies to improve semantic interoperability in health data. J Innov Health Inform. 2015; 22(2): 309-15. PMID: 26245245 DOI: 10.14236/jhi.v22i2.159 [PubMed]

34. Crane S, Comer RS, Arenson AD, Draucker C. Using REDCap to facilitate web-based therapeutic intervention research. Nurs Res. 2019; 68(6): 483-7. PMID: 31693554 DOI: 10.1097/NNR.0000000000000367 [PubMed]

35. Gadsden T, Bateman-Steel CR, Chaverot S, Ressler 
KA, Chee K, Redwood L, et al. Using a computerised database (REDCap) to monitor influenza vaccination coverage of healthcare workers and staff in South Eastern Sydney local health district. Aust Health Rev. 2020. Online ahead of print. PMID: 32853535 DOI: 10.1071/AH20006 [PubMed]

36. Ahmad FA, Payne PRO, Lackey I, Komeshak R, Kenney K, Magnusen B, et al. Using REDCap and Apple ResearchKit to integrate patient questionnaires and clinical decision support into the electronic health record to improve sexually transmitted infection testing in the emergency department. J Am Med Inform Assoc. 2020; 27(2): 265-73. PMID: 31722414 DOI: 10.1093/jamia/ocz182 [PubMed]

37. Fernández Lozano I, Osca Asensi J, Alzueta Rodríguez J. Spanish implantable cardioverter-defibrillator registry: 15th official report of the Spanish society of cardiology electrophysiology and arrhythmias section (2018). Rev Esp Cardiol (Engl Ed). 2019; 72(12): 1054-64. PMID: 31727564 DOI: 10.1016/j.rec.2019.10.002 [ubMed]

38. Gonçalves H, Reis H, Bonhorst D. Portuguese national registry of cardiac electrophysiology (2015/2016). Revista portuguesa de cardiologia. 2020; 39(5): 23741.

39. Parreira L. National registry of cardiac electrophysiology 2015/2016: Better late than never? Revista portuguesa de cardiologia. 2020; 39(5): 243-4.

40. Staziaki PV, Kim P, Vadvala HV, Ghoshhajra BB. Medical registry data collection efficiency: A crossover study comparing web-based electronic data capture and a standard spreadsheet. J Med Internet Res. 2016; 18(6): e141. PMID: 27277523 DOI: 10.2196/jmir.5576 [PubMed]

41. Atalyan AV, Kolesnikova LI, Kolesnikov SI, Grjibovski AM, Suturina LV. Research electronic data capture (REDCap) for building and managing databases for population-based biomedical studies. Ekologiya Cheloveka (Human Ecology). 2019; 2: 52-9.

42. Tomko RL, Gray KM, Oppenheimer SR, Wahlquist AE, McClure EA. Using REDCap for ambulatory assessment: Implementation in a clinical trial for smoking cessation to augment in-person data collection. Am J Drug Alcohol Abuse. 2019; 45(1): 26-
41.
PMID:
29513609
DOI:
10.1080/00952990.2018.1437445 [PubMed]

43. Griffon N, Pereira H, Djadi-Prat J, García MT, Testoni $\mathrm{S}$, Cariou M, et al. Performances of a solution to semiautomatically fill eCRF with data from the electronic health record: Protocol for a prospective individual participant data meta-analysis. Stud Health Technol Inform. 2020; 270: 367-71. PMID: 32570408 DOI: 10.3233/SHTI200184 [PubMed]

44. Vawdrey DK, Weng C, Herion D, Cimino JJ. Enhancing electronic health records to support clinical research. AMIA Jt Summits Transl Sci Proc. 2014; 2014: 102-8. PMID: 25954585 [ $\underline{\text { PubMed] }}$

45. Brundin-Mather R, Soo A, Zuege DJ, Niven DJ, Fiest K, Doig CJ, et al. Secondary EMR data for quality improvement and research: A comparison of manual and electronic data collection from an integrated critical care electronic medical record system. J Crit Care. 2018; 47: 295-301. PMID: 30099330 DOI: 10.1016/j.jcrc.2018.07.021 [PubMed]

46. Won B, Carey GB, Tan Y-HC, Bokhary U, Itkonen M, Szeto K, et al. The Chicago thoracic oncology database consortium: A multisite database initiative. Cureus. 2016; 8(3): e533. PMID: 27092293 DOI: 10.7759/cureus.533 [PubMed]

47. Callen J. Evaluation research studies essential to ensuring health information systems meet the needs of users, including patients. Health Inf Manag. 2016; 45(1): 3-4. PMID: 27105480 DOI: $10.1177 / 1833358316639457$ [PubMed]

48. Haried P, Claybaugh C, Dai H. Evaluation of health information systems research in information systems research: A meta-analysis. Health Informatics J. 2019; 25(1): 186-202. PMID: 28441893 DOI: $10.1177 / 1460458217704259$ [PubMed]

49. Kragelund SH, Kjærsgaard M, Jensen-Fangel S, Leth RA, Ank N. Research electronic data capture (REDCap®) used as an audit tool with a built-in database. J Biomed Inform. 2018; 81: 112-8. PMID: 29649526 DOI: 10.1016/j.jbi.2018.04.005 [PubMed]

50. Oremus M, Sharafoddini A, Morgano GP, Jin X, Xie F. A computer-assisted personal interview app in research electronic data capture for administering time trade-off surveys (REDCap): Development and pretest. JMIR Form Res. 2018; 2(1): e3. PMID: 30684429 DOI: 10.2196/formative.8202 [PubMed] 